\title{
Sex differences in fear of pain: item-level analysis of the Fear of Pain Questionnaire III
}

\author{
Sara MVambheim' \\ Roald A Øien ${ }^{1,2}$ \\ 'Department of Psychology, UiT, The \\ Arctic University of Norway, Troms $\varnothing$, \\ Norway; ${ }^{2}$ Yale University, School of \\ Medicine, Child Study center, New \\ Haven, CT, USA
}

\author{
This article was published in the following Dove Press journal: \\ Journal of Pain Research \\ 7 April 2017 \\ Number of times this article has been viewed
}

Objectives: This study aimed to investigate sex differences in fear of pain (FOP) measured by the Fear of Pain Questionnaire III (FPQ-III) in a nonclinical sample. The FPQ-III is a selfreport inventory measuring FOP, with 30 items, divided into three subscales: Severe, Minor and Medical Pain.

Methods: A total of 185 subjects participated (49.7\% females) in this study. Sex differences on overall FOP, the subscales, and at item level were examined. One-way analysis of variance tested the association between sex and FOP, measured by overall FOP and the subscales. Ordinal regression analysis enabled item-level analysis of the FPQ-III and was conducted to explore further specificity of FOP in males compared to females.

Results: Overall FOP and fear of Severe Pain was significantly higher in females than in males, as measured by the FPQ-Total and the FPQ-Severe. Moreover, females were more likely to report higher FOP than males on 16 items $(p<0.05)$. Further inspection revealed that females scored significantly higher than males on all items on the Severe Pain subscale. When controlling for multiple comparisons six items reached significance $(p<0.001)$. Five of these items belonged to the subscale Severe Pain. When controlling for overall FOP one item, also from the Severe Pain subscale, reached significance $(p<0.001)$.

Conclusion: There are sex differences in severe FOP, with higher FOP in females compared to males. Potential explanations are sex differences in the 1) psychosocial mechanisms of fear and anxiety, and 2) emotional reactions to and interpretation of FPQ-III Severe Pain items.

Keywords: fear of pain, FOP, fear of pain questionnaire III, FPQ-III, pain, sex differences

\section{Introduction}

Fear of pain (FOP) and anxiety are often measured as covariates in experimental and clinical pain studies. Fear and anxiety are typically defined as related but distinct constructs, with fear representing an alarm reaction toward a presented threat, and anxiety a future-focused fear or worry. ${ }^{1}$ Previous studies have revealed that females are more sensitive to pain $^{2}$ and have lower pain threshold and tolerance than their male peers. ${ }^{3}$ A recent meta-analysis reviewing sex differences in experimental pain research concluded that hormones and depression are not the contributing factors to sex differences in pain, but that anxiety, cognitive, and social factors are. ${ }^{4}$ FOP has been associated with increased sensitivity to pain and reduced pain threshold. ${ }^{5,6}$ There is an evidence for the existence of sex differences here as well, with findings suggesting that high levels of FOP reduce pain tolerance in females, but not in males. ${ }^{3}$ Other studies have reported that anxiety may increase pain ${ }^{1}$ and that anxiety is more strongly associated with pain in males than in females. ${ }^{2,7}$
Correspondence: Sara M Vambheim Department of Psychology, UiT, The Arctic University of Norway, PO box 6070, N-9037 Tromsø, Norway Tel +4797569020

Email sara.m.vambheim@uit.no 
Sex differences in FOP measured by the Fear of Pain Questionnaire III (FPQ-III) have been reported in several studies, ${ }^{8-12}$ and the tendency is that FOP is higher in females than in males. Sullivan et al found sex differences in FPQIII endorsed FOP. However, FOP did not predict pain report, and anxiety was not correlated with FOP and pain report. ${ }^{10}$ Moreover, by using path analyses, significant paths were found from trait to state anxiety, from trait anxiety to catastrophizing, and from catastrophizing to pain report. This could indicate that FOP has a stronger association with avoidance of pain, than the pain experience itself. ${ }^{13}$ Another possibility is that the measurement of FOP by the FPQ-III is too general, as suggested by Sullivan et al. ${ }^{10}$ While these findings on sex differences in FOP could simply indicate that females fear pain to a greater degree than males, the composition of some questions on the FPQ-III, and their potential influence, should not be discounted. For example, some FPQ-III items describe situations that involve serious pain with potentially fatal outcomes. If these items tend to evoke different responses in males and females, for example, FOP in males while females are more likely to experience anxiety or fear of dying, it may lead to sex differences in FOP reflected on FPQ-III measurements. Higher specificity at item level may address some of these uncertainties, and could potentially lead to a more precise measure of FOP in both males and females. Thus, the development of instruments for measuring FOP that are sensitive enough to 1) detect FOP and 2) distinguish fear from other psychological measures such as anxiety in both males and females is important.

The FPQ-III has become a widely used assessment device for self-reported FOP in both clinical and nonclinical samples. ${ }^{12}$ While taking the FPQ-III, respondents are asked to rate their degree of fear toward certain imagined scenarios involving pain. The FPQ-III has three subscales: fear of Severe, Minor and Medical Pain, and the questionnaires' psychometric properties have been investigated. ${ }^{11,12,14,15}$ Some studies have reported that the FPQ-III has a good internal consistency and moderate-to-good test-retest stability. ${ }^{12}$ However, others have concluded that the model has a poor fit. ${ }^{14,16}$ As previously mentioned, sex differences in FOP measured by the FPQ-III have been reported repeatedly. ${ }^{8,11,12}$ Yet it should be noted that inconsistencies remain in the extant literature in this area, with some studies reporting sex differences in overall FOP, while differences are limited to the subscales in other studies. However, throughout these studies the direction of the differences between males and females has remained consistent, with higher FOP in females than in males. To the best of our knowledge, no study has addressed sex differences related to measures of FOP by the FPQ-III through content item analysis to date. This study aims to 1) investigate sex differences in FOP measured by the FPQ-total, the FPQ-subscales and at FPQ-item-level and 2) assess the appropriateness of the significant items in relation to measurements of pain. We hypothesized higher FOP in females than in males, and that this difference would be reflected by sex differences on FPQ-total, the subscales and at item level.

\section{Methods}

\section{Participants}

A total of 185 healthy college students were included in the study ( $49.7 \%$ females, mean age: 21,62 , range: $18-30$ years; $50.3 \%$ males, mean age: 24 , range: $19-32$ years). Data from three different samples were pooled. All the three studies were experimental pain studies. Subjects with previous or present serious injuries, psychological and/or physiological disorders were excluded from participation. The FPQ-III and an informed consent form were then filled in. The studies were approved by the Regional Committee for Medical Research Ethics North Norway.

\section{Measures}

The FPQ-III measures pain-related fear on a 30 -item questionnaire. ${ }^{12}$ Each question presents a situation involving pain, and participants are asked to rate FOP on a 5-point Likert scale. High scores reflect high FOP ( $1=$ not afraid at all, $5=$ extremely afraid). Responders are asked to rate their FOP involved in the situations described, for example, breaking your neck. The scale is divided into three subscales consisting of 10 questions, represented as Severe Pain (e.g., being involved in a car accident), Minor pain (e.g., biting your tongue), and Medical pain (e.g., receiving an injection in your mouth). The FPQ-III was designed to measure respondents' FOP, clinically and nonclinically, in patients and healthy individuals. ${ }^{12} \mathrm{~A}$ Norwegian version of the FPQ-III, translated and back translated by Lyby et al, was used in this study. ${ }^{17}$

\section{Statistical analyses}

One-way analysis of variance (ANOVA) with FPQ-III Total score and FPQ-III Severe Pain score as outcomes were conducted to examine overall endorsed FOP. An ordinal regression analysis was conducted to further explore the specificity of FOP in males versus females by examining the FPQ-III on an item-level basis. The item-level analysis might provide more specific measures of endorsed FOP than subscale analysis. The ordinal regression analysis was first conducted without controlling for FPQ-III Total score. After 
which, the second analysis was performed while controlling for the FPQ-III Total score. The FPQ-III Total score was centered to the unweighted mean of the FPQ-III Total mean value for males and females. Females were used as reference group, leading to interpretation of the beta with a focus on female advantage (less likely to score higher than males, positive beta) or disadvantage (more likely to score higher than males, negative beta). Bonferroni correction for multiple comparisons was applied and the $\alpha$-level was set to 0.001 .

\section{Results}

One-way ANOVAs were conducted to analyze sex differences in FOP measured by FPQ-III Total and the subscales. In line with aim (1) statistically significant differences between males and females on FPQ-III Total scores were found $(F(1,184)=12.29, p=0.001)$. Descriptive statistics showed that this was due to higher FPQ-III scores in females $(m=77.3)$ than in males $(m=69.3)$. The difference between males and females on the Severe Pain subscale was also significant $(F(1,184)=24.18, p<0.001)$. Again, females scored significantly higher than males. No significant sex differences were found on the subscales Medical Pain $(F(1,184)=2.37$, $p=0.125)$ and Minor Pain $(F(1,184)=2.44, p=0.119)$. Mean scores and standard deviations for males and females are presented in Table 1.

An ordinal regression analysis, without controlling for overall FOP (FPQ-III Total), but adjusted for multiple comparisons, revealed that females were significantly more likely to score higher than males on six items $(p<0.001)$. Among these, five items were categorized as Severe Pain and one item as Minor Pain. Thus, females scored significantly higher than males on half of the items constituting the Severe Pain subscale. Seven more items were significant on $p=0.05$ (Table 1). Closer inspection revealed that on $p<0.05$, all items on the Severe Pain subscale reached significance.

When controlling for overall FOP, one item, a Severe Pain subscale item (item 10), met significance at $p<0.001$. However multiple items were significant at $p<0.050$ (items 1 , $5,12,15,22$, and 29). Among these items, two were Severe,

Table I Participant demographics

\begin{tabular}{llll}
\hline & Total & Male & Female \\
\hline N & I85 & 93 & 92 \\
Mean of FPQ-III Total (SD) & $73.3($ I5.7) & $69.3(I 5.9)$ & $77.3($ I4.6) \\
Mean of FPQ-III Severe (SD) & $32.5(7.5)$ & $30.0(7.4)$ & $35.2(6.9)$ \\
Mean of FPQ-III Medical (SD) & $22.8(6.7)$ & $22.0(6.6)$ & $23.6(6.8)$ \\
Mean of FPQ-III Minor (SD) & I7.9 (5.3) & I7.3 (5.7) & I8.5 (4.9) \\
\hline
\end{tabular}

Abbreviations: FPQ III, Fear of Pain Questionnaire III; SD, standard division. two were Medical, and two were Minor Pain subscale items. Females scored lower FOP than males on the two Medical Pain subscale items, as indicated by the positive beta weights (items 15 and 29) (Table 2).

\section{Discussion}

This study revealed sex differences in FOP as shown by the relatively higher FPQ-III scores in females compared to males. In this sample, females had higher overall FOP and more fear of Severe Pain, as measured by FPQ-III Total and FPQ-III Severe Pain. Further inspection revealed that the sex differences in fear of Severe Pain influenced the measure of overall FOP. Thus, suggesting that the sex differences on FPQ-III Total were due to sex differences on Severe Pain subscale items. The higher FOP in females than in males found in the present study is in line with previous studies. ${ }^{14,15}$

To quickly summarize some of the findings from previous studies on the FPQ-III, McNeil and Rainwater reported sex differences on overall, Severe, Medical, and Minor Pain subscales. ${ }^{12}$ Osman et al reported sex differences on the Severe and Medical Pain subscales. ${ }^{11}$ Others have reported sex differences on the Severe Pain subscale only. ${ }^{8}$ These studies clearly agree that sex differences in FOP as measured by the FPQ-III exist, and that FOP is higher in females than males. To our knowledge, no studies have reported higher FOP in males than in females on overall or subscale levels, yet inconsistencies persist across studies regarding how these differences are expressed.

One possible explanation of the observed sex difference in fear of Severe Pain is that some of the items might reflect psychological measures other than FOP in females. An increasing number of studies have shown that pain and psychological measures such as fear and anxiety are closely related, and that their association with, or relationship to, pain may differ between males and females. ${ }^{2,7,18}$ While anxiety has been found to increase pain in both sexes, the association between pain and anxiety is stronger in males than in females. ${ }^{18}$ Accordingly, higher levels of anxiety are more strongly associated with higher levels of pain in males than in females. In chronic pain patients, overall anxiety sensitivity is higher in females than in males, but males have higher levels of pain-related anxiety, than females. ${ }^{2}$ Furthermore, high levels of FOP reduce pain tolerance in females, but not in males. ${ }^{3}$ This could explain why females express higher levels of stress, anxiety, and increased negative affect compared to males, ${ }^{19}$ and may be relevant for understanding the findings from this study. In our sample, females scored significantly higher than males on the Severe Pain subscale. 
Table 2 Item-level analysis FPQ-III

\begin{tabular}{|c|c|c|c|c|c|c|}
\hline \multirow[t]{2}{*}{ Item } & \multicolumn{3}{|c|}{ (2a) Main effect of gendera } & \multicolumn{3}{|c|}{ (2b) Main effect of gender } \\
\hline & $\boldsymbol{\beta}$ & SE & $p$-Value & $\boldsymbol{\beta}$ & SE & p-Value \\
\hline Car accident (Severe) & -1.10 & 0.278 & $<0.001 *$ & -0.73 & 0.293 & $0.012 * *$ \\
\hline Biting tongue (Minor) & -0.38 & 0.279 & $0.17 \mid$ & 0.16 & 0.300 & 0.958 \\
\hline Breaking arm (Severe) & -0.56 & 0.268 & $0.037 * *$ & -0.13 & 0.283 & 0.655 \\
\hline Cut tongue on envelope (Minor) & -0.13 & 0.271 & 0.617 & 0.33 & 0.289 & 0.256 \\
\hline Heavy object head (Severe) & -0.97 & 0.271 & $<0.001 *$ & -0.59 & 0.283 & $0.038 * *$ \\
\hline Break leg (Severe) & -0.66 & 0.268 & $0.014 * *$ & -0.21 & 0.280 & 0.457 \\
\hline Hit elbow (Minor) & -0.41 & 0.277 & 0.134 & 0.12 & 0.297 & 0.679 \\
\hline Blood sample (Medical) & -0.03 & 0.279 & 0.927 & 0.48 & 0.303 & 0.112 \\
\hline Slam car door hand (Severe) & -0.78 & 0.270 & $0.004 * *$ & -0.47 & 0.282 & 0.096 \\
\hline Fall down stairs (Severe) & -1.16 & 0.278 & $<0.00 I^{*}$ & -0.92 & 0.290 & $<0.001 *$ \\
\hline Injection arm (Medical) & -0.21 & 0.274 & 0.439 & 0.39 & 0.299 & 0.189 \\
\hline Burn fingers (Minor) & -0.08 & 0.282 & 0.774 & 0.79 & 0.331 & $0.017 * *$ \\
\hline Break neck (Severe) & -0.74 & 0.285 & $0.010 * *$ & -0.30 & 0.307 & 0.324 \\
\hline Injection hip (Medical) & -0.50 & 0.267 & 0.059 & 0.08 & 0.283 & 0.786 \\
\hline Splinter in foot removed (Medical) & 0.14 & 0.288 & 0.619 & 0.65 & 0.319 & $0.042 * *$ \\
\hline Remove particle from eye (Medical) & -0.20 & 0.263 & 0.446 & 0.32 & 0.279 & 0.256 \\
\hline Injection mouth (Medical) & -0.18 & 0.265 & 0.489 & 0.36 & 0.285 & 0.207 \\
\hline Face burned by cigarette (Severe) & -0.71 & 0.272 & $0.009 * *$ & -0.33 & 0.282 & 0.238 \\
\hline Paper-cut finger (Minor) & -0.23 & 0.284 & 0.409 & 0.41 & 0.322 & 0.202 \\
\hline Stitches lip (Medical) & -0.42 & 0.268 & 0.114 & 0.04 & 0.287 & 0.875 \\
\hline Remove foot wart (Medical) & -0.66 & 0.274 & $0.015^{* *}$ & -0.21 & 0.295 & 0.481 \\
\hline Shaving cut (Minor) & -1.35 & 0.300 & $<0.001 *$ & -0.96 & 0.324 & $0.003 * *$ \\
\hline Hot drink (Minor) & -0.18 & 0.280 & 0.526 & 0.34 & 0.299 & 0.261 \\
\hline Soap eyes (Minor) & -0.31 & 0.291 & 0.286 & -0.01 & 0.309 & 0.981 \\
\hline Terminal illness (Severe) & -0.95 & 0.281 & $<0.001 *$ & -0.58 & 0.301 & 0.054 \\
\hline Tooth pulled (Medical) & -0.34 & 0.264 & 0.195 & 0.23 & 0.282 & 0.407 \\
\hline Vomiting food poisoning (Severe) & -0.93 & 0.275 & $<0.001 *$ & -0.50 & 0.286 & 0.081 \\
\hline Sand eyes (Minor) & 0.31 & 0.272 & 0.257 & 0.18 & 0.296 & 0.531 \\
\hline Tooth drilled (Medical) & 0.17 & 0.265 & 0.512 & 0.66 & 0.283 & $0.018 * *$ \\
\hline Muscle cramp (Minor) & -0.67 & 0.277 & $0.015^{* *}$ & -0.22 & 0.292 & 0.452 \\
\hline
\end{tabular}

Notes: $\beta$ negative values indicate females score higher than males; $\beta$ positive values indicate females score lower than males. aMain effect of gender without controlling for overall fear of pain. 'Main effect of gender controlling for overall fear of pain. *Significant $p<0.050$. **Significant after Bonferroni adjustment ( $p<0.00 \mathrm{I})$.

Abbreviations: FPQ III, Fear of Pain Questionnaire III; SE, standard error.

We hypothesized that the Severe Pain subscale items could have been interpreted or understood differently in males and females, possibly due to divergent levels of overall anxiety and pain-related anxiety. This may in turn have produced the observed sex differences. Some of the most contrasting effects between males and females were found in their responses to Severe Pain subscale items, which included item 1 ("automobile accident"), 13 ("breaking your neck"), and 25 ("having a terminal illness causing daily pain"). Females' responses to these items might reflect more symptoms of anxiety rather than FOP itself. Previous studies have reported that females are, for example, more afraid of dying compared to males. ${ }^{20,21}$ Therefore, females may be more fearful of serious incidents, and thereby respond with higher FOP than males to such items. Females' responses to these items might therefore more accurately reflect higher levels of anxiety than FOP. Thus, the Severe Pain subscale may potentially measure something other than FOP in females than in males, such as fear of dying, fear of being disabled, overall anxiety, or existential anxiety. This study defined fear and anxiety as related constructs, but with some distinctions. The findings of higher levels of severe FOP in females, might be related to the interpretation of the Severe Pain subscale items. For example, "Being in an automobile accident", "Having a heavy object hit you in the head", "Breaking your neck", and "Having a terminal illness that causes you daily pain" might not only represent FOP. Such items could also elicit anxiety related to the consequences and implications these serious happenings might have effect on, for example, familial factors and caregiver responsibilities.

One of the FPQ-III items involve daily pain as a comorbidity to terminal illness. Most healthy individuals have no 
experience with pain related to this terminal illness. This is highly relevant for the sample in this study, which consisted of young, healthy participants (mean age: 22.8 years). It is likely that these items measure anxiety, for example, and not the FOP associated with the specific situation. Females report more fear and score higher on measures of trait anxiety than males. ${ }^{22}$ Thus, these items may be problematic when the FPQ-III is utilized to measure FOP in healthy individuals. The finding of less pronounced sex differences on the subscales with less serious outcomes, again raises the question if higher levels of anxiety in females than in males might influence the Severe Pain subscale. Sex differences in interpretations of possible consequences from the presented situations may explain this finding. Furthermore, specificity of some of the FPQ items could improve the ability to measure FOP equally in healthy males and females. Exchanging items where large sex differences are expressed, with other items describing situations where severe pain is involved, might improve the FPQ-III's ability to measure FOP more equally in males and females. As previously mentioned, most healthy individuals have no experience with or relation to serious accidents or injuries, such as one may expect after a car accident or breaking the neck. It may be argued that the Severe Pain subscale does not present situations exclusively related to pain infliction. Inclusion of items presenting other pain involving situations may be more appropriate in relation to measurements of pain and FOP. A possible way of further developing the FPQ-III could be to exchange some of these items with other items that healthy participants more easily can relate to. This may be situations involving moderate-to-high levels of pain, such as postoperative pain, migraine, appendicitis, urinary infection, pyelitis, dislocation of a shoulder, elbow or knee, and tooth pain.

Another possible explanation of the findings from this study is that gender role expectations of pain influence males and females differently when confronted with reporting FOP. Previous studies have shown that pain behavior is influenced by contextual factors, such as socialization, cultural expectations, and feminine and masculine gender role expectations. ${ }^{23-25}$ Klonoff et al reported that males were less likely to report pain than females, and furthermore, were embarrassed when reporting pain. ${ }^{26}$ When conducting a study where experimenters were instructed to dress up and behave in ways meant to elicit gender-related cues, Levine and De Simone found that the sex of the experimenter influenced pain report in males. ${ }^{27}$ The results revealed that males reported significantly lower pain to female experimenters compared to male experimenters. Similar findings have been reported later. ${ }^{28}$ Thus, the importance of gender role stereotypes and their possible contribution to pain behavior cannot be entirely discounted. Gender role stereotypes might have contributed to the findings of the higher FOP in females than in males in this study. In this study, the FPQ-III was administered to the participants in the laboratory. Participants filled in the questionnaire while sitting in the laboratory together with an experimenter. When the participants had finished filling in the questionnaire it was collected by the experimenter. In many cultures, masculine gender roles decreases pain behavior, whereas feminine gender roles increase pain expression. ${ }^{29}$ Male participants in this study may have underscored FOP, possibly due to gender role expectations or stereotypes. However, as these constructs were not measured, this would be a matter of speculation. Future investigations could examine this issue further, for example, by measuring level of masculinity and femininity in addition to FOP or designing a study where experimenter sex and participant sex is crossed and balanced.

The finding that females reported higher FOP on some of the Minor and Medical Pain subscales items, in this study, is in line with previous findings. Fredrikson et al reported that females have higher fear of injections, dentists, and injuries, compared to males. ${ }^{30}$ Females worry, ruminate, and display more negative affectivity than males. According to the results from this study, females are more afraid of burning their fingers, cutting themselves while shaving, having a muscle cramp (Minor Pain), and having a wart removed by a doctor (Medical Pain), compared to males. However, these differences did not contribute to sex differences at subscale level. In addition to the items with fatal or potential for fatal outcome, females were more afraid of being injured by falling, hit or burned by an object, food poisoning, and breaking a bone (Severe Pain), compared to males. Thus, although there are some sex differences on all three subscales, the Minor and Medical Pain subscales seem to be better adjusted for sex than the Severe Pain subscale.

The FPQ-III is designed to measure FOP, ${ }^{12}$ but we argue that it does not sensitively distinguish between FOP and anxiety. The Severe Pain subscale items involving fatal or potentially fatal outcome may elicit different psychological responses in males and females, and thereby produce the differences observed in this and other studies. ${ }^{8-12}$ Thus, there are several potential implications associated with the findings from this study. Pain is not solely a result of nociceptive intensity. Psychological factors influence pain experience, pain expression, and pain inhibition. ${ }^{26}$ There is a distinction between sensory and affective components of pain, and 
both fear and anxiety constitutes the affective dimension of pain. Although fear is related to the immediate and present unpleasantness experienced together with pain, anxiety is merely associated with fears or worries about the long-term implications pain might have. ${ }^{1}$ If higher FOP measured by the FPQ-III reflects fear in males, but anxiety in females, use of FPQ-III measures as covariates in experimental and clinical studies may lead to erroneous or biased conclusions. Fear and anxiety may have opposite effects on pain, illustrated by hyperalgesic responses in the presence of anxiety, and hypoalgesic responses in the presence of fear. ${ }^{1}$ This may partly explain the finding by Lyby et al. ${ }^{17}$ In that study it was reported that FOP was significantly higher in females than in males. Furthermore, FOP was related to reduced pain inhibition in females, but not in males. ${ }^{9}$ Those findings may have been influenced by sex differences in pain-related anxiety, not sex differences in pain-related fear, measured by the FPQ-III. However, only overall mean FOP scores was reported, thus limiting the possibility to reconcile findings with this study.

If the FPQ-III measure different affective components of pain in males and females, our findings may have clinical implications as well. Distinguishing between anxiety and FOP may thus be of importance, for example, in the work with optimizing clinical treatment. Refinement of existing models, or development of new ones, should include fear and anxiety as separate constructs. However, this study included healthy participants only. Thus, results from clinical samples may be divergent, and findings from this could be generalizable to nonclinical samples only.

The fairly young age of the participants in our sample may represent a limitation, as expression of FOP has been found to vary between younger and older populations. ${ }^{15}$ Furthermore, this study utilized a Norwegian version of the FPQ-III, and had a relatively small sample size. Future studies investigating sex differences in FOP measured by the FPQIII should include data from other versions across language, and age groups. Confirmatory and exploratory factor analytic approaches with a focus on sex differences may provide a better model, adjusted for the differences induced by sex.

\section{Conclusion}

Understanding sex differences in pain is of crucial importance to succeed in the development of better and targeted pain treatments. This study found that healthy females score higher on Severe Pain subscale FPQ-III items than males. The FPQIII is designed to measure FOP, but it does not sensitively distinguish between FOP and anxiety. Possible explanations are sex differences in psychosocial and interpretative responses to Severe Pain subscale items. Studies have shown that anxiety is a better predictor of pain in males than in females, and that high levels of FOP reduce pain tolerance in females, but not in males. Therefore, future research should aim to develop FOP measures that sensitively discriminate between fear and anxiety.

\section{Acknowledgments}

The study was supported by the Bial Foundation and the University of Tromsø, Tromsø, Norway. The publication charges were funded by a grant from the publication fund of UiT, The Arctic University of Norway. The authors would like to acknowledge Logan Hart BA, Yale Child Study Center and Dr Frederick Shic, PhD, at University of Washington for their contributions.

\section{Author contributions}

Both authors contributed in the data analysis. SMV wrote the manuscript with contributions from RAØ. Both authors read and approved the final manuscript.

\section{Disclosure}

The authors report no conflicts of interest in this work.

\section{References}

1. Rhudy JL, Meagher MW. Fear and anxiety: divergent effects on human pain thresholds. Pain. 2000;84(1):65-75.

2. Frot M, Feine JS, Bushnell CM. Sex differences in pain perception and anxiety. A psychophysical study with topical capsaicin. Pain. 2004; 108(3):230-236.

3. Thibodeau MA, Welch PG, Katz J, Asmundson GJG. Pain-related anxiety influences pain perception differently in men and women: a quantitative sensory test across thermal pain modalities. Pain. 2013; 154(3):419-426.

4. Racine M, Tousignant-Laflamme Y, Kloda LA, Dion D, Dupuis G, Choinière $\mathrm{M}$. A systematic literature review of 10 years of research on sex/gender and pain perception - part 2: do biopsychosocial factors alter pain sensitivity differently in women and men? Pain. 2012;153(3): 619-635.

5. George SZ, Hirsh AT. Psychologic influence on experimental pain sensitivity and clinical pain intensity for patients with shoulder pain. J Pain. 2009;10(3):293-299.

6. Hirsh AT, George SZ, Bialosky JE, Robinson ME. Fear of pain, pain catastrophizing, and acute pain perception: relative prediction and timing of assessment. J Pain. 2008;9(9):806-812.

7. Riley JL, Robinson ME, Wade JB, Myers CD, Price DD. Sex differences in negative emotional responses to chronic pain. J Pain. 2001; 2(6):354-359.

8. Horn ME, Alappattu MJ, Gay CW, Bishop M. Fear of severe pain mediates sex differences in pain sensitivity responses to thermal stimuli. Pain Res Treat. 2014;2014(5):1-7.

9. Lyby PS, Aslaksen PM, Flaten MA. Variability in placebo analgesia and the role of fear of pain - an ERP study. Pain. 2011;152(10):2405-2412.

10. Sullivan MJL, Thorn B, Rodgers W, Ward LC. Path model of psychological antecedents to ain experience: experimental and clinical findings. Clin J Pain. 2004;20(3):164. 
11. Osman A, Breitenstein JL, Barrios FX, Gutierrez PM, Kopper BA. The fear of pain questionnaire-III: further reliability and validity with nonclinical samples. J Behav Med. 2002;25(2):155-173.

12. McNeil DW, Rainwater AJ. Development of the fear of pain questionnaire-III. J Behav Med. 1998;21(4):389-410.

13. Vlaeyen JW, Linton SJ. Fear-avoidance and its consequences in chronic musculoskeletal pain: a state of the art. Pain. 2000;85(3):317-332.

14. Roelofs J, Peters ML, Deutz J, Spijker C, Vlaeyen JWS. The Fear of Pain Questionnaire (FPQ): further psychometric examination in a nonclinical sample. Pain. 2005;116(3):339-346.

15. Albaret MC, Sastre MTM, Cottencin A, Mullet E. The fear of pain questionnaire: factor structure in samples of young, middle-aged and elderly European people. Eur J Pain. 2004;8(3):273-281.

16. Asmundson GJG, Bovell CV, Carleton NR, McWilliams LA. The Fear of Pain Questionnaire - Short Form (FPQ-SF): factorial validity and psychometric properties. Pain. 2008;134(1):51-58.

17. Lyby PS, Aslaksen PM, Flaten MA. Is fear of pain related to placebo analgesia? J Psychosom Res. 2010;68(4):369-377.

18. Robinson M, Dannecker E, George S, Otis J, Atchinson J, Fillinghim R. Sex differences in the associations among psychological factors and pain report: a novel psychophysical study of patients with chronic low back pain. J Pain. 2005;6(7):463-470.

19. Bagozzi RP, Wong N, YiY. The role of culture and gender in the relationship between positive and negative affect. Cogn Emot. 1999;13(6):641-672.

20. Howze AR. Death Anxiety and Psychotherapy: An Examination of Counselor Trainees' Reactions to Death-Related Issues. The Degree Doctor of Philosophy. 2001.
21. Cotton A. Is there a relationship between death anxiety and engagement in lethal behaviors among African-American students? OMEGA -J Death Dying. 1996;34(3):233-245.

22. McLean CP, Anderson ER. Brave men and timid women? A review of the gender differences in fear and anxiety. Clin Psychol Rev. 2009; 29(6):496-505.

23. Wise EA, Price DD, Myers CD, Heft MW, Robinson ME. Gender role expectations of pain: relationship to experimental pain perception. Pain. 2002;96(3):335-342.

24. Koutantji M, Pearce SA, Oakley DA. The relationship between gender and family history of pain with current pain experience and awareness of pain in others. Pain. 1998;77(1):25-31.

25. McGrath PA. Psychological aspects of pain perception. Arch Oral Biol. 1994;39:S55-S62.

26. Klonoff EA, Landrine H, Brown M. Appraisal and response to pain may be a function of its bodily location. J Psychosom Res. 1993;37(6): 661-670.

27. Levine FM, Lee De Simone L. The effects of experimenter gender on pain report in male and female subjects. Pain. 1991;44(1):69-72.

28. Aslaksen PM, Myrbakk IN, Høifødt RS, Flaten MA. The effect of experimenter gender on autonomic and subjective responses to pain stimuli. Pain. 2007;129(3):260-268.

29. Fillingim RB. Sex, gender, and pain: women and men really are different. Curr Rev Pain. 2000;4(1):24-30.

30. Fredrikson M, Annas P, Fischer H, Wik G. Gender and age differences in the prevalence of specific fears and phobias. Behav Res Ther. 1996; 34(1):33-39.
Journal of Pain Research

\section{Publish your work in this journal}

The Journal of Pain Research is an international, peer reviewed, open access, online journal that welcomes laboratory and clinical findings in the fields of pain research and the prevention and management of pain. Original research, reviews, symposium reports, hypothesis formation and commentaries are all considered for publication.

\section{Dovepress}

The manuscript management system is completely online and includes a very quick and fair peer-review system, which is all easy to use. Visit http://www.dovepress.com/testimonials.php to read real quotes from published authors. 